\section{Trust in the ZAGA method}

When referring your patients for dental implant treatment, it's essential to work with a clinical team that utilises cutting-edge techniques.

The Centre for Oral-Maxillofacial and Dental Implant Reconstruction is based at the Manchester ICE Hospital and has been recognised as one of only 20 international ZAGA centres around the world. Professor Cemal Ucer, Specialist Oral Surgeon, gained accreditation following training with Dr Carlos Aparicio in Barcelona.

The ZAGA method (Zygoma Anatomy-Guided Approach) focuses on adapting clinical tools and concepts to the patient's anatomy, rather than the other way around. It is a philosophy centred primarily on patient well-being.

Discover how the experienced team at the Centre for Oral-Maxillofacial and Dental Implant Reconstruction could help your patients by contacting Professor Ucer at ice@ucer. uk or Mel Hay at mel@mdic.co.

\section{Award-winning bonding}

ONE COAT 7 UNIVERSAL is a light-cured, single-component bonding agent from COLTENE.

Offering outstanding strength and sealing, with nanofiller technology, clinicians praise its versatility, that no prior etching is required and that one drop goes a long way.

The indications for ONE COAT 7 UNIVERSAL include:

$\rightarrow$ Adhesion of composite materials, compomers and ceramic materials to enamel and dentine

$\rightarrow$ Adhesion of composite material on ceramic, composite material, zirconium oxide, metal and amalgam

$\rightarrow$ Dentine sealing.

COLTENE develops and distributes products for upgraded dentistry and ONE COAT 7 UNIVERSAL is just one part of its brilliant restorative line.

To find out more visit www.coltene.com, email info.uk@coltene.com or call 01444235486.

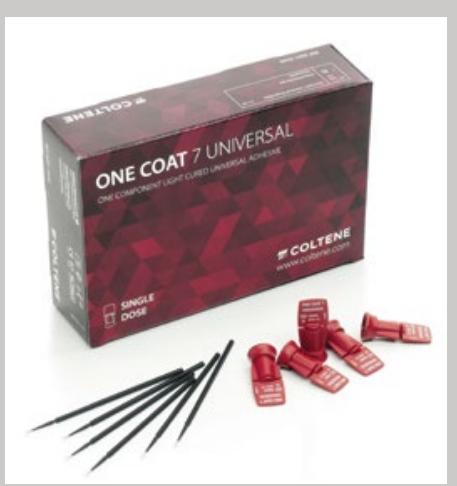

\section{Safeguard against Candida auris}

To safeguard against Candida auris, an emerging super fungus that could pose a threat to the dental practice, try the Steri-7 Xtra range from Initial Medical.

Proven to kill up to $99.9999 \%$ of pathogens in just seconds, Steri-7 Xtra disinfectants are comprised of Didecyldimethylammonium chloride, Benzalkonium chloride and Polyhexamethylene biguanide to ensure ultimate protection.

Together with its unique reactive barrier technology that protects surfaces between cleans, practices can be sure to minimise the risk of Candida auris, ensuring patients and staff alike are kept safe during their time in surgery.

To find out more about how Steri-7 Xtra can benefit you, please visit www.initial. co.uk/medical or Tel: 08708504045 .
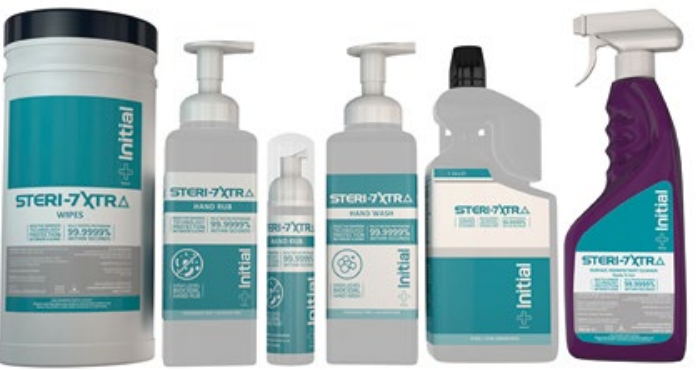

\section{Need a lab?}

CosTech Dental Laboratory is proud to offer professionals a number of excellent advantages including:

$\rightarrow$ A family owned and run laboratory since 1977

$\rightarrow$ Dedicated NHS and Private departments

$\rightarrow$ A daily Personal Pickup and Delivery Service (in some areas)

$\rightarrow$ DAMAS accredited since 2011

$\rightarrow$ An Express Turnaround service for urgent cases

$\rightarrow$ Free postage on all standard work

$\rightarrow$ Competitive prices

$\rightarrow$ Tracked post on private crowns and bridges

$\rightarrow$ Five-year guarantee on all private $\mathrm{C} \& \mathrm{~B}$ cases (patient guarantee card supplied)

$\rightarrow$ One year guarantee on all NHS C\&B cases.

Offering a huge array of products including dental implants, NHS zirconia crowns, mouth guards, tooth whitening kits and more, CosTech prides itself on reliability, quality and excellent customer service.

You can find out more by contacting CosTech by visiting www.costech.co.uk or calling 01474320076.

\section{Speed up reprocessing}

W\&H aims to help clinicians optimise their handpiece maintenance procedures with the Assistina TWIN, which features two chambers that can be used alternately to speed up reprocessing.

The Assistina TWIN nebulises the oil to produce a dispersible mist that is discharged through the handpiece at high pressure. This not only removes contamination from within the instrument, but also ensures even the most inaccessible parts are consistently coated.

Spray channels can be cleaned and components oiled in just 10 seconds per handpiece, enabling you to process up to 360 instruments per hour.

To find out more visit www.wh.com/ en_uk, call 01727874990 or email office. uk@wh.com. 